\title{
ANÁLISE DO PROCESSO DE PLANEJAMENTO NO CUSTO E NO PRAZO FINAL DE UMA OBRA
}

\author{
Isabela Pieroni \\ Graduada em Engenharia Civil pelo CEFET/RJ, Rio de Janeiro, RJ, Brasil \\ isapieroni@gmail.com \\ Elaine Garrido Vazquez
} Doutora em Engenharia Civil pela Universidade Federal do Rio de Janeiro (UFRJ), Rio de Janeiro, RJ, Brasil Professora do Departamento de Construção Civil da UFRJ, Rio de Janeiro, RJ, Brasil elainevazquez@poli.ufrj.br

João de Jesus dos Santos Doutor em Engenharia Civil pela PUC-Rio, Rio de Janeiro, Brasil Professor do Departamento de Engenharia Civil do CEFET/RJ, Rio de Janeiro, RJ, Brasil paraduc@yahoo.com.br

Lais Amaral Alves Mestre em Engenharia Civil pela Universidade Federal do Rio de Janeiro (UFRJ), Rio de Janeiro, RJ, Brasil Professora do Departamento de Engenharia Civil do CEFET/RJ, Rio de Janeiro, RJ, Brasil aalves.lais@gmail.com

\section{RESUMO}

A competitividade do mercado atual da construção civil criou a necessidade de reduzir prazos e custos na execução das obras. Por causa dessa necessidade e a grande dificuldade para atendê-la, devido à falta de uma cultura de planejamento, as empresas de construção estão investindo cada vez mais tempo e dinheiro na implantação de sistemas de gestão, buscando atingir um planejamento físico-financeiro mais eficiente. O presente trabalho abordará a relação entre planejamento e custo dentro de uma obra. Serão levantados conceitos e técnicas de ambos. Por meio de um estudo de caso, serão analisados o orçamento e o cronograma de um empreendimento, e serão mostrados os desvios em relação ao planejamento inicial, os motivos dos desvios encontrados, os impactos causados e a importância de um planejamento mais eficiente para que melhores resultados sejam alcançados.

Palavras-chave: Construção Civil. Planejamento. Orçamento. Prazo. Custo. 


\title{
PROJECT
}

\begin{abstract}
The competitiveness of the current real state market has created the need of reducing time and costs during a building execution. Because of the importance of that need, and the great difficulty in achieve it, mainly due the lack of a management and planning culture, construction companies are increasing significantly their investments in implementations of management systems, seeking an efficient physical-financial planning as a goal. This paper will compare the relationship between planning and cost inside of a construction site. Concepts and techniques will be shown along this article. Through of a case study, budget and schedule of projects will be analyzed, and also deviations of the initial planning will be shown. The reasons and impacts of those deviations will also remembered, even as the importance of an efficient planning to achieve better results.
\end{abstract}

Keywords: Construction. Planning. Budget. Deadline. Cost.

\section{INTRODUÇÃO}

Deficiências no planejamento e no controle estão entre as principais causas da baixa produtividade do setor da construção civil, de suas elevadas perdas e da baixa qualidade dos seus produtos. O mercado da construção civil, devido à rapidez das transformações tecnológicas, associadas à competitividade cada vez mais acirrada e abrangente entre as empresas, exige profissionais cada vez mais capacitados. As empresas e os contratantes exigem qualidade associada à produtividade e cronogramas cada vez mais apertados. A satisfação do cliente tornou-se prioridade, e é preciso se adaptar a um novo processo de execução de projeto e obra. A produção e o planejamento, portanto, devem ser elaborados dentro desta nova realidade.

A produtividade está relacionada com a qualidade e desempenho, com a eliminação do desperdício de materiais, mão de obra e equipamentos, acompanhados da utilização de técnicas, tecnologias e normas que respeitem o meio ambiente. Devese sempre estar em busca de boas soluções com qualidade e custos compatíveis de execução, associando ações que elevem o processo produtivo, aproveitando os novos conceitos de planejamento e de execução de obras.

Precisa-se considerar o projeto do empreendimento, definindo e especificando a maior quantidade de informações e detalhes possíveis para que se tenha uma execução mais racional e simplificada. Uma obra de qualidade, realizada dentro do prazo e custo 
previstos, resulta de um bom projeto e de um bom planejamento.

Este trabalho tem como objetivo analisar o processo de planejamento na construção civil e sua influência na melhoria do custo e do prazo das obras. Por meio de um estudo de caso, visa analisar a possível redução dos prejuízos, aumentando a produtividade, a qualidade e melhorando a imagem das empresas.

\section{DESENVOLVIMENTO}

Parte principal do artigo, que contém a exposição ordenada e pormenorizada do assunto tratado. Divide-se em seções e subseções, conforme a NBR 6024, que variam em função da abordagem do tema e do método.

De acordo com Mattos (2010), o planejamento de obra é um dos principais aspectos do gerenciamento, que envolve também orçamento, compras, gestão de pessoas, comunicação, etc. Ao planejar, o gerente dota a obra de ferramentas importantes para priorizar suas ações, acompanhar e comparar o andamento dos serviços, com a linha de base referencial e tomar providências em tempo hábil, quando algum desvio é detectado.

O planejamento não se restringe a dimensionar equipes, quantificar insumos, programar entregas, orçar, encontrar o caminho crítico num diagrama de Gantt. Planejar, além disso, é selecionar a melhor tecnologia, obter o máximo da racionalização de cada processo, ordenar os processos e as equipes, equacionar as interfaces (THOMAZ, 2001).

Para Gehbauer (2002), o porte e a complexidade das obras, a multiplicidade de soluções técnicas, assim como os limites de prazo e custo, tornam necessária a realização de um planejamento eficiente.

O planejamento inclui muitas atividades, as quais devem ser identificadas, analisadas, coordenadas e gerenciadas, sendo o resultado de um plano de ação, contendo as definições antecipadas das decisões que deverão ser tomadas durante o processo de realização da obra, incluindo organização, direção e controle (XAVIER, 2008).

A organização é uma tarefa da qual se estabelece a melhor forma de se comporem os recursos físicos, humanos e financeiros para se obter o melhor desempenho. A direção é a ação por meio da qual se define quando, como, onde, por quem, e com quais recursos devem ser executadas as tarefas planejadas (XAVIER, 2008).

O controle de um determinado empreendimento é a ação de medir o resultado de uma operação e comparar o resultado obtido com o padrão estabelecido, para verificar 
se atende ou não aos limites de tolerâncias pré-estabelecidos (XAVIER, 2008).

Planejamento é o processo de tomada de decisões interdependentes, visando uma situação futura desejada. Pode-se dizer que o planejamento é um método para definir qual a melhor sequência das ações que vão gerar valor. Devem-se conhecer os recursos financeiros disponíveis para cada empreendimento (XAVIER, 2008).

Para Ackoff (1976), planejamento pode ser considerado ?]a definição de um futuro desejado e de meios eficazes de alcançá-lo?. De acordo com essa definição, notase que a tomada de decisão está intrinsecamente relacionada com o planejamento, pois é através do processo de decisão que as metas estabelecidas nos planos podem ser cumpridas.

Na construção civil, é constatada com grande frequência, a ausência ou a inadequação do planejamento das obras. Essa deficiência do planejamento resulta em consequências desastrosas para uma obra e para a empresa que a executa. Encontramse casos de não cumprimento de prazos, estouros de orçamento, atrasos injustificados, indisposição do construtor com o cliente e até de litígios judiciais para recuperação de perdas e danos (MATTOS, 2010).

A melhor maneira de minimizar esses impactos é produzir um planejamento lógico e racional. Assim, dispõe-se de um instrumento com critérios técnicos, de fácil manuseio e interpretação (MATTOS, 2010).

\section{ESTUDO DE CASO}

Para análise de custo e prazo, será apresentada a análise da construção de um empreendimento comercial da Empresa $X$, abordando as comparações entre o custo de construção do orçamento estimativo, o orçamento base cravado antes da execução do empreendimento, e as alterações até o custo real após a conclusão da obra. Será analisado também, o planejamento e o prazo de execução, com suas alterações no decorrer da construção, o motivo das mesmas e as possíveis soluções para os atrasos e aumentos orçamentais encontrados.

A Empresa $X$, responsável pela incorporação e construção do empreendimento analisado, possui diversos procedimentos que padronizam todas as etapas de execução da obra, assim como as etapas complementares, incluindo a execução do orçamento e do planejamento da obra. O estudo de caso analisado compreende um terreno de área de aproximadamente $1.769,41 \mathrm{~m}^{2}$, localizado no bairro da Tijuca, cidade do Rio de Janeiro. 
A empresa em estudo é do ramo de construção civil e atua nos setores residenciais e comerciais.

O empreendimento é comercial, com área total construída de 10.829,46 $\mathrm{m}^{2}$, composto de um único bloco, com 215 salas e 5 lojas. Possui 1 subsolo de garagem, pavimento térreo onde ficam localizadas as lojas e vagas de garagem, pavimento jirau, composto pelo mezanino das lojas e estacionamento, um pavimento garagem, 9 andares tipo com 22 salas, 1 andar com 17 salas, dentre elas, 6 com terraços descobertos, e pavimento telhado.

\subsection{Pré-orçamento x Orçamento base}

Feita a atualização do pré-orçamento (base abril de 2012) para o orçamento base (base abril de 2013) tem-se um valor de $\mathrm{R} \$ 26.771 .878,95$ (49.984,74 INCC), já o orçamento base tem um total de R\$ 26.392.439,51 (49.276,31 INCC).

Quando comparado o pré-orçamento com o orçamento base, existem variações maiores em alguns grupos, devido à diferença de quantidade de informações fornecidas nas duas etapas do orçamento, mas o valor total do orçamento base está dentro da estimativa inicial do pré-orçamento, tendo apenas uma variação de $\mathrm{R} \$ 397.439,44$.

\subsection{Orçamento Base $x$ Custo Final}

Percebe-se ao comparar os orçamentos base atualizado $\mathrm{R} \$ 31.310 .313,53$ (49.276,31 INCC) e o custo final R\$27.016.703,92 (42.519,01 INCC), que ocorreu uma redução de $\mathrm{R} \$$ 4.293.609,61 (6.757,30 INCC).

As divergências entre o pré-orçamento e o orçamento base, são, em sua maioria, devido à falta de projetos finalizados no período em que são realizados os levantamentos de quantitativo, troca de fornecedores, atraso na execução da obra, situações não previstas, etc. Os grupos analisados, por sofrerem grande variação de valor, tiveram também uma diferença de percentual em relação ao orçamento total, quando analisados o orçamento base e o custo real. Essas variações podem ser analisadas na Figura 1.

Figura 1 - Comparativo Orçamento Base x Orçamento Real 


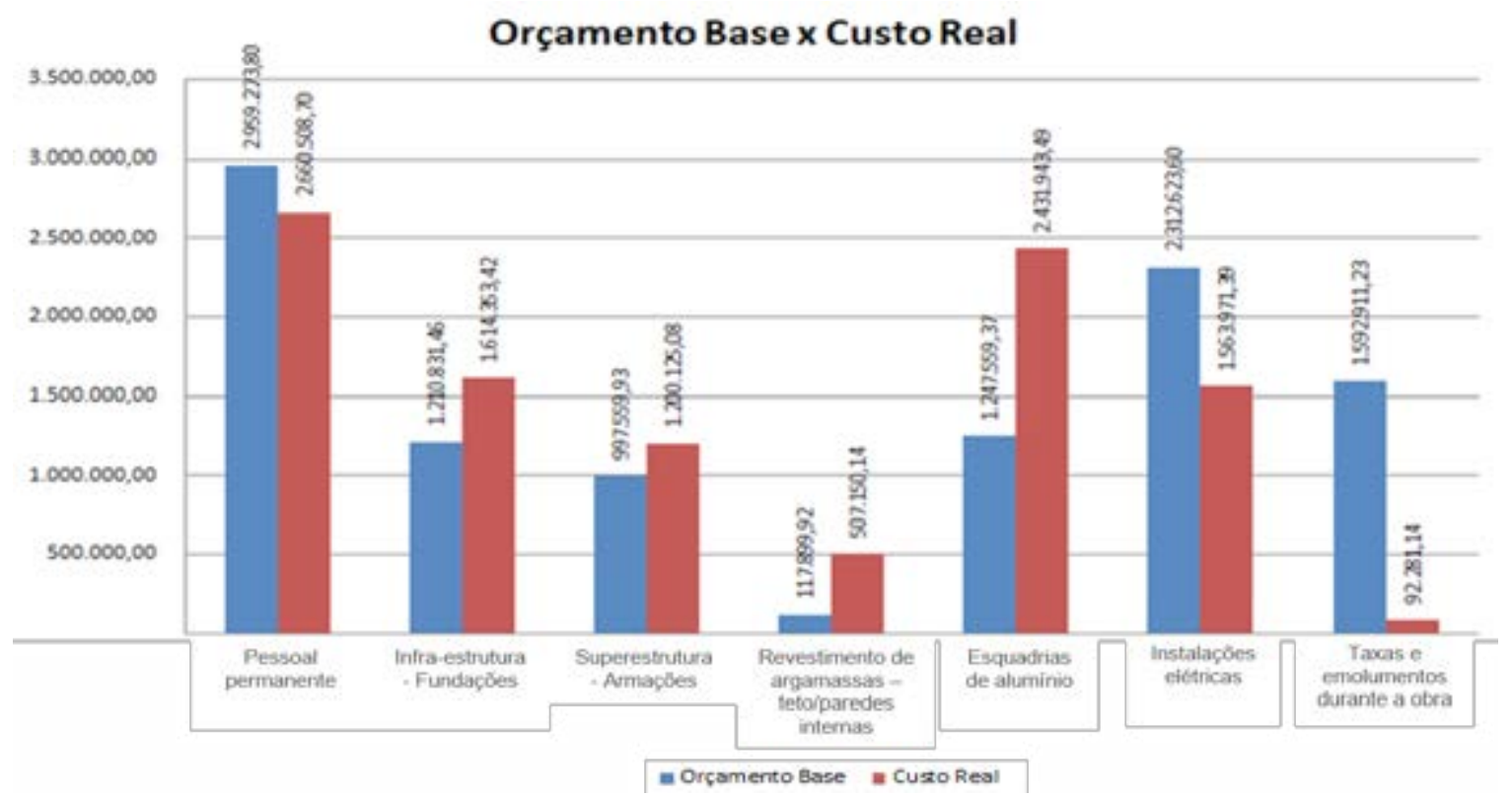

O Grupo de pessoal permanente, que é referente aos funcionários da Empresa $X$ que atuarão na obra, foi calculado baseado no prazo determinado inicialmente, que seria de 23 meses. A obra atrasou, e, devido a isso, houve aumento na quantidade de meses previsto para alguns cargos, porém, o grupo teve uma redução em reais. Isso se deve ao fato de que, no decorrer da obra, houve variações em relação aos funcionários que formavam a equipe inicial.

O grupo 8 agrega toda execução da fundação e serviços relacionados a ela. 0 aumento no grupo foi devido a vários serviços não previstos inicialmente, em função da variedade de itens contidos nele. Devido às interferências da fundação dos vizinhos encontradas no terreno, houve atraso na obra, e alguns serviços tiveram que ser prolongados, causando aumento no grupo. Outro item responsável pelo aumento do grupo foi o reforço estrutural. Foi realizado controle tecnológico em todo o concreto utilizado na obra. Eram feitos testes nas amostras depois de 7, 28 e 63 dias. Foram encontradas resistências abaixo do aceitável nas sapatas P27, P48, P45 E P52, e, após análise do calculista, foi decidido pela realização de reforço estrutural. A realização desse reforço gerou uma contratação no valor de $\mathrm{R} \$ \mathbf{6 8 . 8 0 0 , 0 0}$. Também foi contratado um serviço de revestimento de PVC para as cortinas do subsolo, que não havia sido previsto inicialmente. Essa contratação gerou um aumento de $R \$ 76.152,80$.

Foi contratada, inicialmente, uma empresa para execução de armação. A empresa iniciou os serviços, porém não apresentou um bom rendimento. Foi decidida entre a 
equipe de engenharia e a gerencia da obra, a substituição da empresa. No momento da troca do fornecedor, haviam sido executados apenas quatro pavimentos. Essa troca

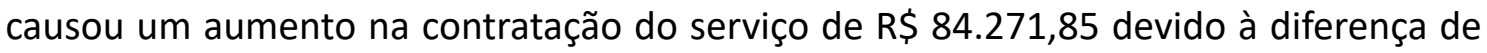
preços dos dois fornecedores. A nova empresa apresentou melhores resultados em relação à empresa anterior, com mais velocidade e organização na execução da obra.

Ogrupo 18 é referente ao revestimento de argamassa. Inicialmente, o revestimento interno das paredes do prédio seria de gesso, como definido em projeto. Porém antes do início da execução do serviço, a premissa foi alterada, sendo decido pela substituição do revestimento de gesso pelo emboço, ocasionando um distrato da empresa contratada inicialmente. Foi realizada uma contratação no valor total de $\mathrm{R} \$ 385.902,87$, referente à execução do emboço interno, o que ocasionou um considerável aumento no grupo.

O orçamento base foi realizado com uma proposta para a execução do serviço de esquadria de alumínio junto a uma empresa, no valor de R\$ 1.109.326,99. Porém, após o início da obra, foi decido que o serviço seria realizado por outra empresa, melhor cotada no mercado. Apesar de a escolha ser vantajosa pela garantia da qualidade do serviço e diminuição do risco de atraso na execução do mesmo, o fechamento junto à nova empresa ficou em $\mathrm{R} \$ 2.177 .590,00$, o que acarretou num aumento de $\mathrm{R} \$ 1$ 1.068.263,01, um valor considerável se tratando de um único serviço e um aumento de $96 \%$ em relação à contratação inicial.

O grupo 34 é referente aos serviços e materiais das instalações elétricas. Houve uma redução no grupo devido ao orçamento base ter utilizado uma proposta de uma determinada empresa, realizada antes da liberação dos projetos executivos. A proposta que foi utilizada é de $\mathrm{R} \$ 2.284 .750,00$, porém, o serviço foi contratado com outra empresa, cujo valor de contrato foi $\mathrm{R} \$ 1.513 .000,16$. Sendo assim, o grupo teve uma redução de $\mathrm{R} \$ 771.749,84$, referente a essa mudança de empresa contratada e ao fechamento da proposta inicial num período anterior à liberação dos projetos executivos, o que ocasiona prováveis e consideráveis mudanças de projeto.

O grupo 45 de Taxas e Emolumentos é composto por taxas de ligação das instalações provisórias e definitivas, seguro de obra e contingência. Na cravação do orçamento base, foi definida uma verba de contingência no valor de $\mathrm{R} \$ 1.416 .166,26$, que é calculada baseada na diferença encontrada entre o orçamento base e o préorçamento, com o objetivo de suprir possíveis problemas durante a execução da obra, que não foram previstos anteriormente. Como não foi necessária a utilização da verba, houve o estorno da mesma no final da obra, causando a maior redução no custo final da 
obra.

\subsection{Análise do prazo}

Houve mudanças no do prazo de execução da obra devido a inúmeras situações, causando no final, um aumento do prazo definido antes do início da obra. Na Tabela 1, verifica-se as datas de início e término, bem como o prazo previstos em cada etapa.

Tabela 1 - Comparativo Orçamento Base x Orçamento Real

\begin{tabular}{|c|c|c|c|c|c|c|}
\hline DATAS & CONTRATUAL & $\begin{array}{c}\text { PRÉ } \\
\text { ORÇAMENTO }\end{array}$ & PDP INICIAL & PDP & ATUALIZADO & REAL \\
\hline INÍCIO & $01 / 02 / 2013$ & $01 / 02 / 2013$ & $01 / 02 / 2013$ & $01 / 04 / 2013$ & $01 / 04 / 2013$ & $01 / 04 / 2013$ \\
\hline TÉRMINO & $31 / 03 / 2015$ & $30 / 12 / 2014$ & $30 / 12 / 2014$ & $31 / 12 / 2014$ & $28 / 02 / 2015$ & $08 / 05 / 2015$ \\
\hline $\begin{array}{c}\text { PRAZO } \\
\text { MESES }\end{array}$ & 26 & 23 & 23 & 21 & 23 & 25 \\
\hline
\end{tabular}

\section{CONSIDERAÇÕES FINAIS}

O presente trabalho analisou o planejamento e sua influência nos resultados finais do custo de uma obra. Pode-se observar através do estudo de caso, que a maior parte das variações encontradas nos dois âmbitos poderiam ter sido evitadas, ou pelo menos minimizadas, caso houvesse uma melhor análise e uma maior quantidade de informações nas etapas principais.

Quando analisadas as variações do orçamento, percebe-se que grande parte das alterações foram relacionadas com a troca de fornecedores. Esse tipo de alteração pode ser evitado se houver uma avaliação dos fornecedores baseada em seu desempenho em obras anteriores na própria construtora, ou através de uma pesquisa de mercado. Houve também uma mudança de revestimento no caso da troca do gesso pelo emboço, item que deveria ter sido definido previamente com precisão.

A redução referente ao pessoal permanente está diretamente ligada ao planejamento, pois variou devidoà previsão errada do prazo da obra e de dimensionamento da equipe. $O$ grupo 45 de Taxas e Emolumentos durante a obra, que teve a maior variação referente ao orçamento cravado antes da obra, como visto, teve uma variação devido à verba de contingência. Essa verba é adicionada ao orçamento com o intuito de cobrir possíveis situações não previstas antes do início da obra. A necessidade da existência dessa verba mostra a posição da própria construtora em relação a sua possibilidade de falha de previsão. 
Analisando o resultado final das variações do orçamento, verifica-se que ocorreu uma redução em relação ao orçamento base reajustado. Em um primeiro momento, imagina-se que a falta de planejamento é prejudicial devido ao provável aumento no custo da obra. Na grande maioria dos casos, ocorre exatamente isso. Porém, uma redução pode ser considerada favorável quando apresentar uma pequena variação em relação ao orçamento base. No caso estudado, ocorreu uma redução de aproximadamente $14 \%$. Reduções com variações altas são prejudiciais, pois a empresa fica com um dinheiro "preso", que poderia estar sendo investido em outros projetos.

Conclui-se que a obra estudada não teve grandes impactos causados pela falta de assertividade no orçamento e no planejamento, diferente da maioria dos casos, em que as empresas têm grandes prejuízos financeiros e de imagem devido às falhas observadas. Porém, existiram muitos itens em divergência, o que mostra pontos falhos no ciclo de planejamento da empresa. É necessário que as causas apontadas ao longo do estudo de caso sejam observadas e que sirvam de experiência para que haja mudanças, evitando assim futuros resultados indesejados.

\section{REFERÊNCIAS}

ACKOFF, R.L. Planejamento empresarial. Rio de Janeiro: LTC, 1976.

GEHBAUER, Fritz. Planejamento e gestão de obras - Um Resultado Prático da

Cooperação Técnica Brasil-Alemanha. Paraná: Editora CEFET-PR, 2002.

MATTOS, Aldo Dórea. Planejamento e controle de obras. São Paulo: Editora Pini, 2010.

THOMAZ, Ercio. Tecnologia, gerenciamento e qualidade na construção. São Paulo: Editora Pini, 2001.

XAVIER, Ivan. Orçamento, Planejamento E Custos De Obra. São Paulo: Apostila da Fupam - Fundação Para A Pesquisa Ambiental, 2008. 